\title{
The Effect of Antidepressant Medication Treatment on Serum Levels of Inflammatory Cytokines: A Meta-Analysis
}

\author{
Jonas Hannestad*,', Nicole DellaGioia' and Michael Bloch ${ }^{1,2}$ \\ 'Department of Psychiatry, Yale University School of Medicine, New Haven, CT, USA; ${ }^{2}$ Child Study Center, Yale University School of Medicine, \\ New Haven, CT, USA
}

\begin{abstract}
Serum levels of inflammatory cytokines, for example, tumor necrosis factor alpha (TNF $\alpha$ ), interleukin-6 (IL-6), and IL-I beta (IL-I $\beta$ ), are elevated in subjects with major depressive disorder (MDD). The reason why this occurs is unclear. Elevated levels of inflammatory cytokines could be a result of brain dysfunction in MDD. It is also possible that inflammatory cytokines contribute to depressive symptoms in MDD. If the first assumption is correct, one would expect levels to normalize with resolution of the depressive episode after treatment. Several studies have measured changes in cytokine levels during antidepressant treatment; however, the results vary. The purpose of this study was to pool all available data on changes in serum levels of TNF $\alpha$, IL-6, and IL-I $\beta$ during antidepressant treatment to determine whether these levels change. Studies were included if they used an approved pharmacological treatment for depression, patients had a diagnosis of MDD, and serum levels of TNF $\alpha$, IL-6, and/or IL-I $\beta$ were measured before and after treatment. Twenty-two studies fulfilled these criteria. Meta-analysis of these studies showed that, overall, while pharmacological antidepressant treatment reduced depressive symptoms, it did not reduce serum levels of TNF $\alpha$. On the other hand, antidepressant treatment did reduce levels of $\mathrm{IL}-\mathrm{I} \beta$ and possibly those of IL-6. Stratified subgroup analysis by class of antidepressant indicated that serotonin reuptake inhibitors may reduce levels of IL-6 and TNF $\alpha$. Other antidepressants, while efficacious for depressive symptoms, did not appear to reduce cytokine levels. These results argue against the notion that resolution of a depressive episode is associated with normalization of levels of circulating inflammatory cytokines; however, the results are consistent with the possibility that inflammatory cytokines contribute to depressive symptoms and that antidepressants block the effects of inflammatory cytokines on the brain.

Neuropsychopharmacology (20I I) 36, 2452-2459; doi:I0.1038/npp.20 I I.I32; published online 27 July 201 I
\end{abstract}

Keywords: depression; inflammation; TNF; IL-6; IL-I; antidepressant

\section{INTRODUCTION}

Major depressive disorder (MDD) is a prevalent and debilitating disorder the pathogenesis of which is incompletely understood. MDD, in the absence of medical illnesses, is associated with increased levels of the inflammatory cytokines tumor necrosis factor alpha (TNF $\alpha$ ), interleukin-6 (IL-6), and IL-1 beta (IL-1 $\beta$ ) (Howren et al, 2009; Dowlati et al, 2010). There are several potential reasons why elevated levels of inflammatory cytokines are associated with MDD: (1) there may be common etiologies that lead to both MDD and elevated levels of these inflammatory cytokines, without a causal relation between the two phenomena; (2) MDD may cause brain alterations that impair the brain's ability to modulate the immune system via hypothalamic-pituitary-adrenal axis activity and

*Correspondence: Dr J Hannestad, Department of Psychiatry, Clinical Neuroscience Research Unit, Yale University School of Medicine, CMHC-Ribicoff, 34 Park Street, New Haven, CT 06519, USA, Tel: + I 203974 7536, Fax: + I 203974 7662,

E-mail: jonas.hannestad@yale.edu

Received 8 April 20 II; revised I5 June 20I I; accepted I5 June 20I I autonomic outflow; and (3) systemic triggers (eg, exposure to pathogens), genetic differences in the immune system, or differences in the immune system's exposure to commensal microorganisms, may lead to increased production of inflammatory cytokines, which in turn contribute to depressive symptoms (Miller et al, 2009; Raison et al, 2010). Supporting (3) are studies showing that acute and chronic immune stimuli, which increase serum levels of inflammatory cytokines, can elicit depressive symptoms in humans (Reichenberg et al, 2001; Wright et al, 2005; Capuron et al, 2009; Eisenberger et al, 2009; DellaGioia and Hannestad, 2010), and studies showing that anti-inflammatory and anti-TNF $\alpha$ drugs can ameliorate depressive symptoms (Muller et al, 2006; Tyring et al, 2006). If (2) above is true, that is, elevated cytokine levels are a consequence of depression, then the treatment of depression with successful resolution of depressive symptoms would be expected to normalize levels. If, on the other hand, (3) above is true, that is, elevated levels of TNF $\alpha$ and IL-6 is a result of processes inherent to the immune system, then antidepressant treatment may not normalize levels, unless they have a direct effect on innate immune cells. Some studies suggest such a direct effect on the immune system, 
for example, in rodents both sub-chronic (Yirmiya et al, 2001) and acute (Roumestan et al, 2007) administration of antidepressants has anti-inflammatory effects, while some studies in humans did not find this effect (Hannestad et al, 2011). Although multiple studies have measured the effect of antidepressant treatment on circulating cytokine levels in patients with MDD, the results are not consistent. The goal of this meta-analysis was to determine whether pharmacological treatment of MDD is associated with changes in circulating levels of inflammatory cytokines, specifically TNF $\alpha$, IL-6, and IL- $1 \beta$; these cytokines were chosen because they are elevated in depression (Howren et al, 2009; Dowlati et al, 2010).

\section{MATERIALS AND METHODS}

\section{Search Strategy}

PubMed, PsychINFO, EMBASE, and the Cochrane Library were searched by two reviewers (JH and ND) for relevant trials using the following search strategies: (tumor necrosis factor OR interleukin) AND (antidepressant OR serotonin reuptake inhibitor OR tricyclic). The Cochrane Library was also searched using the broader terms 'interleukin AND depressive' and 'tumor necrosis factor AND depressive'. The references of all papers included in this meta-analysis as well as select review papers on this topic were searched for citations of further relevant published and unpublished research. Studies were limited to those that assessed human subjects. There were no language limitations on included studies.

\section{Criteria for Inclusion of Studies in this Review}

Studies were included in this meta-analysis if they examined the effect of a pharmacological treatment for depression (ie, an antidepressant) on serum levels of TNF $\alpha$, IL-6, and/or IL- $1 \beta$. Studies were only included if the pharmacological treatment used was a medication of demonstrated efficacy and approved by FDA for the treatment of MDD. Studies examining the effect of antidepressant treatment on other cytokines or that assessed cytokine production in vitro or ex vivo were not included. Studies of the effect of nonpharmacological treatments for depression (eg, electroconvulsive therapy, psychotherapy, sleep deprivation, herbal remedies, and so on) were not included. Studies were only included if the human subjects had a diagnosis of MDD and were medically healthy adults.

\section{Meta-Analytic Methods}

The primary outcome measure was change in mean serum level of TNF $\alpha$, IL- 6 , or IL- $1 \beta$ over the course of a period of treatment with an antidepressant medication. As different cytokine assays have different sensitivity, comparisons were only made within each study. Some studies presented data in graph form only. Authors were contacted and asked to provide the actual values; when this information was not provided by the author, the mean change in cytokine serum level, and SD were estimated from measuring the published graphs with a ruler.
Standardized mean difference (SMD) was chosen as the summary statistic for meta-analysis and pooled using the generic inverse variance method in RevMan 5. A randomeffects model was chosen for meta-analysis because random-effects models are preferred when there is significant heterogeneity between trials. Publication bias was assessed by plotting the effect size against sample size for each trial (funnel plot). Heterogeneity in changes in cytokine levels was assessed visually from the forest plot of SMD of individual studies. Statistical estimates of heterogeneity were assessed using the $I^{2}$ heterogeneity statistic in RevMan 5. In addition, a sensitivity analysis was performed to examine our decision to use a randomeffect model rather than a fixed-effects model for meta-analysis.

Studies were stratified based on class of antidepressant used (specific serotonin reuptake inhibitor, SSRI; serotonin and norepinephrine reuptake inhibitor, SNRI; and tricyclic antidepressants, TCA). Studies that used $>2$ different antidepressant classes and that did not give cytokine data for each antidepressant class used, were classified as 'Miscellaneous'. For TNF $\alpha$, stratification included only SSRI and Miscellaneous, because there was only one study each which used only a TCA or only an SNRI. For IL-6, stratification included SSRI, TCA, and Miscellaneous, but not SNRI since there was only one study, which used only an SNRI. For IL-1 $\beta$, no stratification was performed because 5 out of 6 studies used SSRIs. We used the test for subgroup differences in RevMan 5 to determine whether subgroups reduced overall heterogeneity. For all statistical analysis we used a significance threshold of $p<0.05$.

\section{RESULTS}

\section{Selection of Studies}

Twenty-two studies, comprising 603 subjects, fulfilled the inclusion criteria (Maes et al, 1995, 1997; Sluzewska et al, 1995; Frommberger et al, 1997; Hinze-Selch et al, 2000; Kubera et al, 2000; Kagaya et al, 2001; Mikova et al, 2001; Kraus et al, 2002; Tuglu et al, 2003; Basterzi et al, 2005; Himmerich et al, 2006; Leo et al, 2006; Sutcigil et al, 2007; Eller et al, 2008; Hernandez et al, 2008; Piletz et al, 2009; Song et al, 2009; Yoshimura et al, 2009; Chen et al, 2010; Jazayeri et al, 2010; Fornaro et al, 2011). Details about these studies are presented in Table 1. Eight studies used more than one class of antidepressant and were classified as miscellaneous; the other studies were classified based on the use of SSRIs, SNRIs, and TCAs. Most (18 out of 22) studies assessed depression severity with the Hamilton Depression Rating Scale (HDRS); only two used the Montgomery-Åsberg Depression Rating Scale. Baseline depression severity was very similar across studies. The weighted mean HDRS score at baseline was $25.5 \pm 1.0$ in the 18 studies that used this scale. The degree of improvement (as a percent reduction from the baseline severity score) was also very homogeneous. In the 18 studies that provided this information, the weighted mean reduction in depression severity was $52 \pm 3 \%$. As a result of such homogeneity in baseline severity and degree of improvement, no metaregression by baseline severity or degree of improvement was performed. With regards to the cytokine assays used, 
Table I Studies Included in the Meta-Analysis

\begin{tabular}{|c|c|c|c|c|c|}
\hline Study & $\mathbf{N}$ & $\begin{array}{l}\text { Cytokine(s) } \\
\text { assessed }\end{array}$ & $\begin{array}{l}\text { Antidepressant } \\
\text { class }\end{array}$ & $\begin{array}{l}\text { Rating scale/baseline } \\
\text { severity/percent reduction }\end{array}$ & Assay type/manufacturer \\
\hline Basterzi et al (2005) & 23 & IL-6 & SSRI & HDRS/2I/49\% & ELISA/Cytlmmune Sciences \\
\hline Eller et al (2008) & 100 & TNF & SSRI & MADRS/29/68\% & Chemiluminescence/lmmulite \\
\hline Frommberger et al (1997) & 10 & IL-6 & TCA & MADRS/34/65\% & Bioassay \\
\hline Himmerich et al (2006) & 67 & TNF & Misc. & HDRS/27/66\% & ELISA/BioSource \\
\hline Hinze-Selch et al (2000) & 22 & TNF & SSRI or TCA & ND & ELISA/Medgenix \\
\hline Jazayeri et al (20।0) & 14 & IL-6, IL-I & SSRI & HDRS/29/64\% & ELISA/Bender MedSystems \\
\hline Kagaya et al (200I) & 12 & TNF, IL-6, IL-I & TCA & $\mathrm{HDRS} / 23 / 49 \%$ & ELISA/BioSource \\
\hline Kraus et al (2002) & 20 & TNF & SNRI & ND & ELISA/Medgenix \\
\hline Maes et al (1997) & 25 & IL-6 & Misc. & $\mathrm{HDRS} / 25 / 47 \%$ & ELISA/Eurogenetics \\
\hline Mikova et al (200I) & 23 & TNF, IL-6 & SSRI and TCA & HDRS/> I 8/ND 9 resp, 5 non resp & ELISA/Eurogenetics \\
\hline Piletz et al (2009) & 12 & TNF, IL-I & SNRI & HDRS/26/58\% & ELISA/Quantikine \\
\hline Sluzewska et al (1995) & 9 & IL-6 & SSRI & $\mathrm{HDRS} / 23 / \mathrm{ND}$ & ELISA/ND \\
\hline Song et al (2009) & 30 & TNF, IL-I & SSRI & $\mathrm{HDRS} / 22 / 50 \%$ & ELISA/GeneMay \\
\hline Sutcigil et al (2007) & 23 & TNF & SSRI & $\mathrm{HDRS} / \sim 26 / \sim 50 \%$ & ELISA/Bender MedSystems \\
\hline Tuglu et al (2003) & 26 & TNF & SSRI & $\mathrm{HDRS} / 27 / 67 \%$ & Chemiluminescence/lmmulite \\
\hline Yoshimura et al (2009) & 51 & TNF, IL-6 & SSRI and SNRI & $\mathrm{HDRS} / 22 / 68 \%$ & ELISA/Quantikine \\
\hline
\end{tabular}

Abbreviations: ELISA, enzyme-linked immunosorbent assay; HDRS, Hamilton Depression Rating Scale; IL-I, interleukin-I; IL-6, interleukin-6; MADRS, MontgomeryÅsberg Depression Rating Scale; ND, no data; SNRI, serotonin norepinephrine reuptake inhibitor; SSRI, serotonin reuptake inhibitor; TCA, tricyclic antidepressant. List of studies included in this meta-analysis. The table shows the number of subjects in each study, the cytokines measured, the antidepressant treatment used (by class), the depression severity measure, the baseline depression severity score, the percent decrease in depression severity, the type of cytokine assay used, and the manufacturer of the assay.

19 out of 22 studies used enzyme-linked immunosorbent assays (ELISA) to measure serum levels of cytokines; however, there was a wide range of manufacturers (Table 1).

\section{Tumor Necrosis Factor Alpha}

A total of 13 studies ( $n=438$ subjects) that measured serum levels of TNF $\alpha$ were included in this meta-analysis (Figure 1). Using the random-effects model, antidepressant treatment had no effect on serum levels of TNF $\alpha$ $(\mathrm{SMD}=-0.13$ (95\% CI: $-0.55,0.29), Z=0.6, p=0.55)$. This did not change when the fixed-effects model was used ( $\mathrm{SMD}=0.09$ (95\% CI: $-0.05,0.23), Z=1.3, p=0.19$ ). There was substantial heterogeneity between studies $\left(\tau^{2}=0.5\right.$; $\left.\chi^{2}=103.7, \mathrm{df}=12, p<0.00001, I^{2}=88 \%\right)$, and the asymmetry in the funnel plot was indicative of possible publication bias. Stratified subgroup analysis showed that there was a significant difference by medication class $\left(\chi^{2}=13.6, \mathrm{df}=1, p=0.0002\right)$, because studies that used SSRI treatment showed greater reduction in TNF $\alpha$ levels. Using the random-effects model, SSRI treatment $(n=199$ subjects) did not have an effect on TNF $\alpha$ levels $(\mathrm{SMD}=-0.67 \quad(95 \%$ CI: $-1.61,0.26), Z=1.4, p=0.16)$; however, using the fixed-effects model there was a trend effect of SSRI treatment on TNF $\alpha$ levels (SMD $=-0.20(95 \%$ CI: $-0.40,0.01), Z=1.9, p=0.06$ ). There was substantial heterogeneity between SSRI studies $\left(\tau^{2}=1.1 ; \chi^{2}=65.1\right.$, $\left.\mathrm{df}=4, p<0.00001, I^{2}=94 \%\right)$.

\section{Interleukin-6}

A total of 13 studies ( $n=274$ subjects) measured the effect of antidepressant treatment on IL-6 levels and were included in this meta-analysis (Figure 2). Using the random-effects model, antidepressant treatment had no effect on IL-6 levels (SMD $=-0.32$ (95\% CI: $-1.06,0.43$ ), $Z=0.8, p=0.41$ ); however, using the fixed-effects model there was a significant, albeit very small, effect (SMD $=-0.24$ (95\% CI: $-0.43,-0.05), Z=2.5, p=0.01$ ). Similarly, excluding two outliers (Sluzewska et al, 1995; Chen et al, 2010) rendered the overall results statistically significant, albeit with a very small effect (SMD $=-0.38$ (95\% CI: -0.72 , $-0.05), Z=2.3, p=0.02$ ). There was substantial heterogeneity between studies $\left(\tau^{2}=1.7 ; \quad \chi^{2}=186.6, \quad \mathrm{df}=12, \quad p<0.00001\right.$, $\left.I^{2}=94 \%\right)$. Stratified subgroup analysis showed that there was a significant difference by medication class $\left(\chi^{2}=51.4, \mathrm{df}=2\right.$, $p<0.00001)$ because studies that used SSRI treatment showed 


\begin{tabular}{|c|c|c|c|c|c|}
\hline \multirow{2}{*}{$\frac{\text { Study or Subgroup }}{\text { TNF SSRI }}$} & \multirow[t]{2}{*}{ Weight } & \multirow[t]{2}{*}{$\begin{array}{l}\text { Std. Mean Difference } \\
\text { IV, Random, } 95 \% \mathrm{Cl}\end{array}$} & \multirow[t]{2}{*}{ Year } & \multicolumn{2}{|c|}{$\begin{array}{l}\text { Std. Mean Difference } \\
\text { IV, Random, } 95 \% \text { CI }\end{array}$} \\
\hline & & & & & \\
\hline Tuglu 2003 & $7.6 \%$ & $-1.59[-2.22,-0.96]$ & 2003 & . & \\
\hline Leo 2006 & $7.4 \%$ & $-1.01[-1.67,-0.35]$ & 2006 & & \\
\hline Sutcigil 2007 & $7.3 \%$ & $-1.82[-2.51,-1.12]$ & 2007 & & \\
\hline Eller 2008 & $8.8 \%$ & $0.22[-0.05,0.50]$ & 2008 & & \\
\hline Song 2009 & $8.0 \%$ & $0.68[0.16,1.21]$ & 2009 & & \\
\hline Subtotal $(95 \% \mathrm{Cl})$ & $39.1 \%$ & $-0.67[-1.61,0.26]$ & & & \\
\hline \multicolumn{6}{|c|}{$\begin{array}{l}\text { Heterogeneity: } \text { Tau }^{2}=1.05 ; \mathrm{Chi}^{2}=65.12, \mathrm{df}=4(P<0.00001) ; \mathrm{I}^{2}=94 \% \\
\text { Test for overall effect: } Z=1.41(P=0.16)\end{array}$} \\
\hline \multicolumn{6}{|c|}{ TNF miscellaneous } \\
\hline Hinze-Selch 2000 & $7.7 \%$ & $0.45[-0.15,1.04]$ & 2000 & & \\
\hline Mikova 2001 & $7.1 \%$ & $-0.07[-0.81,0.68]$ & 2001 & & \\
\hline Kagaya 2001 & $6.5 \%$ & $-1.28[-2.18,-0.39]$ & 2001 & & \\
\hline Kraus 2002 & $7.6 \%$ & $0.31[-0.31,0.93]$ & 2002 & & \\
\hline Himmerich 2006 & $8.6 \%$ & $0.66[0.31,1.00]$ & 2006 & & - \\
\hline Yoshimura 2009 & $8.4 \%$ & $-0.11[-0.51,0.29]$ & 2009 & & 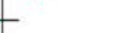 \\
\hline Piletz 2009 & $6.7 \%$ & $0.82[-0.02,1.66]$ & 2009 & & \\
\hline Chen 2010 & $8.3 \%$ & $0.63[0.19,1.06]$ & 2010 & & 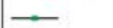 \\
\hline Subtotal $(95 \% \mathrm{Cl})$ & $60.9 \%$ & $0.23[-0.14,0.60]$ & & & \\
\hline \multirow{2}{*}{\multicolumn{6}{|c|}{$\begin{array}{l}\text { Heterogeneity: } \mathrm{Tau}^{2}=0.19 ; \mathrm{Chi}^{2}=25.00, \mathrm{df}=7(P=0.0008) ; \mathrm{I}^{2}=72 \% \\
\text { Test for overall effect: } Z=1.23(\mathrm{P}=0.22)\end{array}$}} \\
\hline & & & & & \\
\hline \multirow{2}{*}{\multicolumn{6}{|c|}{ Heterogeneity: $\mathrm{Tau}^{2}=0.51 ; \mathrm{Chi}^{2}=103.70, \mathrm{df}=12(\mathrm{P}<0.00001) ; \mathrm{I}^{2}=88 \%$}} \\
\hline & & & & & \\
\hline \multicolumn{4}{|c|}{ Test for overall effect: $Z=0.60(P=0.55)$} & -2 & 1 \\
\hline
\end{tabular}

Figure I Effect of antidepressant treatment on TNF serum levels.

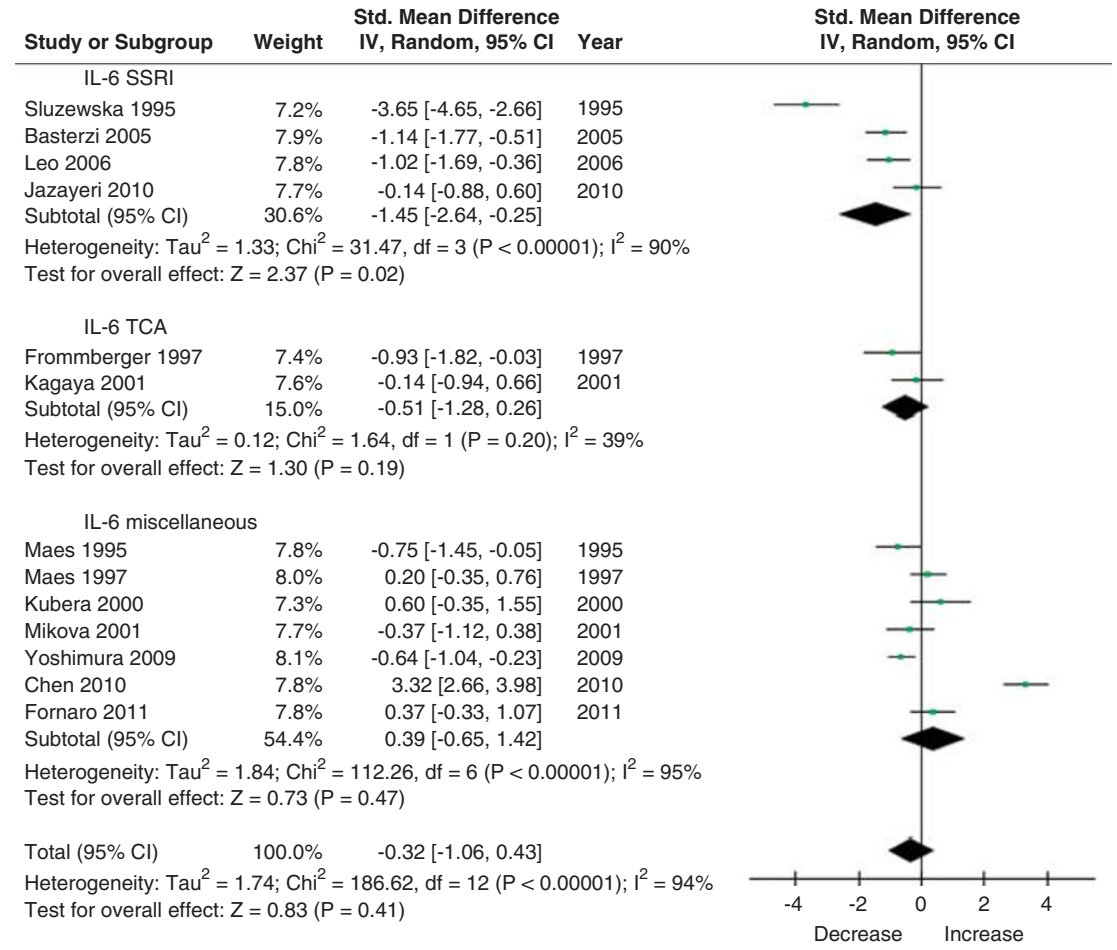

Figure 2 Effect of antidepressant treatment on IL-6 serum levels.

greater reduction in IL-6 levels than studies using other antidepressants. Using the random-effects model, there was a significant effect of SSRI treatment ( $n=79$ subjects) on IL-6 levels (SMD $=-1.45$ (95\% CI: $-2.64,-0.25), Z=2.4, p=0.02)$. Excluding one SSRI outlier (Sluzewska et al, 1995) did not change this (SMD $=-0.80$ (95\% CI: $-1.38,-0.21), Z=2.7$, $p<0.008)$. There was significant heterogeneity between the SSRI studies $\left(\tau^{2}=1.3 ; \chi^{2}=31.5, \mathrm{df}=3, p<0.00001, I^{2}=90 \%\right)$. Using the random-effects model, there was no effect of TCA treatment $(n=24$ subjects) on IL-6 levels (SMD $=-0.51$ (95\% CI: -1.28 , $0.26), Z=1.3, p=0.2$ ).

\section{Interleukin-1 Beta}

A total of six studies ( $n=115$ subjects) measured levels of IL-1 $\beta$ and were included in this meta-analysis (Figure 3). Using the random-effects model, there was a significant effect of antidepressant treatment on IL-1 $\beta$ levels (SMD $=-0.52$ (95\% CI: $-0.83,-0.20), Z=3.23, p<0.001$ ), and there was minimal heterogeneity in the studies that measured changes in IL- $1 \beta$ levels $\left(\tau^{2}=0.04 ; \chi^{2}=6.6, \mathrm{df}=5, p=0.25, I^{2}=24 \%\right)$. Of the six studies that measured IL-1 $\beta$ levels, five used an SSRI for treatment; therefore no stratification by antidepressant class was performed. 


\begin{tabular}{|c|c|c|c|c|}
\hline Study or Subgroup & Weight & $\begin{array}{l}\text { Std. Mean Difference } \\
\text { IV, Random, } 95 \% \mathrm{CI}\end{array}$ & Year & $\begin{array}{l}\text { Std. Mean Difference } \\
\text { IV, Random, } 95 \% \mathrm{CI}\end{array}$ \\
\hline Kagaya 2001 & $8.8 \%$ & $-0.24[-1.23,0.74]$ & 2001 & 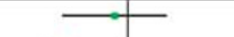 \\
\hline Leo 2006 & $17.0 \%$ & $-0.97[-1.63,-0.31]$ & 2006 & \\
\hline Hernandez 2008 & $24.7 \%$ & $-0.49[-0.99,0.02]$ & 2008 & \\
\hline Song 2009 & $24.2 \%$ & $-0.49[-1.01,0.02]$ & 2009 & \\
\hline Piletz 2009 & $11.2 \%$ & $-1.01[-1.87,-0.15]$ & 2009 & \\
\hline Jazayeri 2010 & $14.2 \%$ & $0.16[-0.58,0.90]$ & 2010 & \\
\hline Total $(95 \% \mathrm{Cl})$ & $100.0 \%$ & $-0.52[-0.83,-0.20]$ & & \\
\hline \multicolumn{5}{|c|}{ Heterogeneity: $\mathrm{Tau}^{2}=0.04 ; \mathrm{Chi}^{2}=6.60, \mathrm{df}=5(\mathrm{P}=0.25) ; \mathrm{I}^{2}=24 \%$} \\
\hline \multicolumn{4}{|c|}{ Test for overall effect: $Z=3.23(P=0.001)$} & $\begin{array}{ll}-2 & -1\end{array}$ \\
\hline
\end{tabular}

Figure 3 Effect of antidepressant treatment on IL-I serum levels.

\section{DISCUSSION}

Meta-analysis of the studies included here failed to show a significant overall effect of pharmacological antidepressant treatment for MDD on serum levels of TNF $\alpha$ and IL-6. On the other hand, it appears that antidepressant treatment reduces IL- $1 \beta$ levels. Using the less stringent fixed-effects model, we found a small effect of antidepressant treatment on IL-6 levels. Similarly, excluding two outliers, the effect of antidepressant treatment on IL-6 levels was statistically significant. Stratified subgroup analysis suggested that SSRI treatment specifically may be associated with a reduction in IL- 6 levels, and perhaps with a reduction in $\mathrm{TNF} \alpha$ levels (when using the less stringent fixed-effects model rather than the random-effects model); however, the results of subgroup analyses are based on a small subsample of studies and must therefore be considered with that caveat in mind.

As a result of the homogeneity in the degree of improvement, no meta-regression was performed. In a large $(n=100)$ study, there was no change in TNF $\alpha$ serum levels in responders or non-responders to SSRI treatment, despite a large difference in the change in depression severity $(74 \%$ reduction in responders $v s 33 \%$ reduction in non-responders) (Eller et al, 2008). In a follow-up study, non-responders were treated with bupropion, and among those who responded there was a $63 \%$ reduction in depression severity, but no change in TNF $\alpha$ levels (Eller et al, 2009). Overall, neither this meta-analysis nor Eller's data support the hypothesis that serum levels of TNF $\alpha$ decrease as a result of improvement in depressive symptoms, or that a decrease in TNF $\alpha$ levels is required for the antidepressant effect. This may suggest that increased $\mathrm{TNF} \alpha$ levels in depression are due to an inherent dysfunction in the immune system and not related to the effects of MDD on the brain.

This meta-analysis suggests that there may be an effect of antidepressants on IL-6 levels, specifically of SSRI treatment. One study found a negative correlation between the reduction in depression severity and the change in serum IL-6 (Yoshimura et al, 2009). In cardiac patients with depression, both SSRI treatment (Pizzi et al, 2009) and cognitive-behavioral therapy (Doering et al, 2007) was associated with a reduction in IL-6 levels. The degree of elevation in IL-6 levels in MDD $(d=0.25$ (95\% CI: 0.18, 0.31) (Howren et al, 2009)) and weighted mean difference $=1.8 \mathrm{pg} / \mathrm{ml}$ (95\% CI: 1.23 to 2.33 ) (Dowlati et al, 2010) is consistent with the degree of reduction in levels with SSRI treatment found here (SMD $=-1.9)$.
Antidepressant treatment appears to have an effect in lowering levels of IL- $1 \beta$, a cytokine for which evidence of an elevation in depression is controversial (Dowlati et al, $2010)$. The degree of elevation in IL- $1 \beta$ levels in one study $(d=0.35$ (95\% CI: 0.03, 0.67)) (Howren et al, 2009) is consistent with the reduction seen here with antidepressant treatment $(\mathrm{SMD}=-0.62)$. Studies of depression co-morbid with other conditions have found that SSRIs lower IL- $1 \beta$ levels, including post-traumatic stress disorder (Tucker et al, 2004) and renal failure (Lee et al, 2004). Recently, Himmerich et al (2010) found that blood levels of IL-1 $\beta$ became undetectable in patients with depression after treatment with antidepressants. At the same time, the proportion of regulatory $\mathrm{T}$ lymphocytes (Treg) increased. As Tregs suppress innate immunity, this may be a mechanism through which antidepressant treatment reduces IL- $1 \beta$ levels, although the converse is also possible, that is, a reduced level if IL- $1 \beta$ permits differentiation of Tregs (Himmerich et al, 2010). Interestingly, a recent study found that tryptophan metabolites can enhance Treg differentiation (Yan et al, 2010); how this may relate to serotonin reuptake inhibition remains to be determined.

In depression, levels of TNF $\alpha$, IL- 6 , and IL- $1 \beta$ are elevated (Howren et al, 2009; Dowlati et al, 2010), however, the reasons for this are not understood. An elevated level of circulating inflammatory cytokines may occur because of a dysfunction in the brain's anti-inflammatory mechanisms, which include the hypothalamic-pituitary-adrenal axis, the efferent vagus (Bierhaus et al, 2003; Pavlov and Tracey, 2005; Shaked et al, 2009), and noradrenergic innervation (Selmeczy et al, 2003). It has long been known that the human brain can modulate IL- $1 \beta$ levels in the periphery (Keppel et al, 1993). Psychological stress can increase peripheral inflammation in humans (Bierhaus et al, 2003; Dickerson et al, 2004; Gundersen et al, 2006; Pace et al, 2006) by interfering with the brain's ability to modulate systemic inflammation. People with low parasympathetic tone show impaired inhibition of TNF $\alpha$ levels after exercise (Weber et al, 2010), indicating poor control of inflammation by the autonomic nervous system. However, if a lack of autonomic control of inflammation were the cause of elevated inflammatory cytokine levels in depression, remission of depressive symptoms would be expected to reduce levels, which the current meta-analysis does not unequivocally show. That is, in the studies included here there was a mean $50 \%$ reduction in depressive symptoms (regardless 
of the class of antidepressant used); however, only SSRIs appeared to have a potential effect on cytokine levels. This suggests that, if elevated levels of these inflammatory cytokines are due to an immune system abnormality (genetic or acquired) in depression or to excess stimulation by pathogen-associated molecules (eg, endotoxin leakage from the gut), treatment with antidepressants may not have an effect on TNF $\alpha$ and IL-6 levels, which is more consistent with our results.

In the studies included here, there was a significant improvement in depression severity (50\% reduction); however, this occurred despite unchanged levels of TNF $\alpha$ and IL-6. This suggests that, even if elevated levels of TNF $\alpha$ and IL-6 contribute to some depressive symptoms (eg, fatigue), treatment with antidepressants may improve such symptoms (presumably through an effect on the brain) without lowering levels of circulating cytokine levels. This is consistent with a recent study in which we showed that pretreatment with an SSRI reduced endotoxin-induced depressive symptoms without an effect on levels of TNF $\alpha$ and IL-6 (Hannestad et al, 2011). It is also possible that in depression certain symptoms do not improve completely because of continued elevations in these cytokines. For instance, IL-6 levels were associated with refractoriness to antidepressant treatment in one study (Yoshimura et al, 2009).

The studies included here indicate that SSRI treatment specifically may decrease levels of IL-1 $\beta$, IL-6, and possibly $\mathrm{TNF} \alpha$, although these results must be interpreted with caution because of the low number of studies that used SSRIs only. On the other hand, it appears that the SNRIs venlafaxine and duloxetine are associated with an increase in levels of, respectively, TNF $\alpha$ (Piletz et al, 2009) and IL-6 (Fornaro et al, 2011). This difference between SSRIs and SNRIs is consistent with the known pro-inflammatory effects of norepinephrine on innate immune cells (Thayer and Sternberg, 2010).

It is important to point out several limitations of this meta-analysis. There was large heterogeneity between studies that measured levels of TNF $\alpha$ and IL-6, and there was significant evidence for publication bias for TNF $\alpha$ studies. It is possible that different pharmacological treatments for depression affect cytokine levels differently as suggested by the stratified subgroup analysis; however, the large degree of heterogeneity remains and the sources of this heterogeneity are not clear. We do not believe assay differences were responsible for the heterogeneity because most studies used ELISA to measure cytokine levels. Similarly, the baseline depression severity of the subjects included in the studies was very similar and therefore an unlikely source of heterogeneity. This meta-analysis was performed with study-level data. Future meta-analyses of patient-level data may clarify some of these questions, which in turn can answer some critical questions about the association between MDD, antidepressant treatment, and cytokine levels.

In summary, this meta-analysis showed that, overall, there was no effect of pharmacological antidepressant treatment on serum levels of TNF $\alpha$, while there was an effect on IL-1 $\beta$ levels and possibly on IL-6 levels. Stratified analysis suggests a possible effect of SSRIs on levels of IL-6 and TNF $\alpha$. Finally, the data analyzed here are not consistent with the notion that the state of depression 'causes' elevated levels of inflammatory cytokines, because levels do not decrease even when patients show improvement in symptoms.

\section{ACKNOWLEDGEMENTS}

We thank Dr Reiji Yoshimura for providing additional data for inclusion in this review. We acknowledge the National Institute of Drug Addiction (K12DA00167; JH), the National Institute of Mental Health (Yale Child Study Center Research Training Program and 1K23MH091240-01; MB), the APIRE/Eli Lilly Psychiatric Research Fellowship (MB), the AACAP/Eli Lilly Pilot Research Award (MB), NARSAD (MB and JH), and UL1 RR024139 from the National Center for Research Resources, a component of the National Institutes of Health, and NIH roadmap for Medical Research (MB and JH).

\section{DISCLOSURE}

The authors declare no conflict of interest.

\section{REFERENCES}

Basterzi AD, Aydemir C, Kisa C, Aksaray S, Tuzer V, Yazici K et al (2005). IL-6 levels decrease with SSRI treatment in patients with major depression. Hum Psychopharmacol 20: 473-476.

Bierhaus A, Wolf J, Andrassy M, Rohleder N, Humpert PM, Petrov $\mathrm{D}$ et al (2003). A mechanism converting psychosocial stress into mononuclear cell activation. Proc Natl Acad Sci USA 100: 1920-1925.

Capuron L, Fornwalt FB, Knight BT, Harvey PD, Ninan PT, Miller AH (2009). Does cytokine-induced depression differ from idiopathic major depression in medically healthy individuals? J Affect Disord 119: 181-185.

Chen YC, Lin WW, Chen YJ, Mao WC, Hung YJ (2010). Antidepressant effects on insulin sensitivity and proinflammatory cytokines in the depressed males. Mediators Inflamm 2010: 573594.

DellaGioia N, Hannestad J (2010). A critical review of human endotoxin administration as an experimental paradigm of depression. Neurosci Biobehav Rev 34: 130-143.

Dickerson SS, Kemeny ME, Aziz N, Kim KH, Fahey JL (2004). Immunological effects of induced shame and guilt. Psychosom Med 66: 124-131.

Doering LV, Cross R, Vredevoe D, Martinez-Maza O, Cowan MJ (2007). Infection, depression, and immunity in women after coronary artery bypass: a pilot study of cognitive behavioral therapy. Altern Ther Health Med 13: 18-21.

Dowlati Y, Herrmann N, Swardfager W, Liu H, Sham L, Reim EK et al (2010). A meta-analysis of cytokines in major depression. Biol Psychiatry 67: 446-457.

Eisenberger NI, Inagaki TK, Rameson LT, Mashal NM, Irwin MR (2009). An fMRI study of cytokine-induced depressed mood and social pain: the role of sex differences. Neuroimage 47: 881-890.

Eller T, Vasar V, Shlik J, Maron E (2008). Pro-inflammatory cytokines and treatment response to escitalopram in major depressive disorder. Prog Neuropsychopharmacol Biol Psychiatry 32: $445-450$.

Eller T, Vasar V, Shlik J, Maron E (2009). Effects of bupropion augmentation on pro-inflammatory cytokines in escitalopramresistant patients with major depressive disorder. J Psychopharmacol 23: 854-858.

Fornaro M, Martino M, Battaglia F, Colicchio S, Perugi G (2011). Increase in IL-6 levels among major depressive disorder patients after a 6-week treatment with duloxetine $60 \mathrm{mg} / \mathrm{day}$ : a preliminary observation. Neuropsychiatr Dis Treat 7: 51-56.

Frommberger UH, Bauer J, Haselbauer P, Fraulin A, Riemann D, Berger $M$ (1997). Interleukin-6-(IL-6) plasma levels in depression and schizophrenia: comparison between the acute 
state and after remission. Eur Arch Psychiatry Clin Neurosci 247: 228-233.

Gundersen Y, Opstad PK, Reistad T, Thrane I, Vaagenes P (2006). Seven days' around the clock exhaustive physical exertion combined with energy depletion and sleep deprivation primes circulating leukocytes. Eur J Appl Physiol 97: 151-157.

Hannestad J, DellaGioia N, Ortiz N, Pittman B, Bhagwagar Z (2011). Citalopram reduces endotoxin-induced fatigue. Brain Behav Immun 25: 256-259.

Hernandez ME, Mendieta D, Martinez-Fong D, Loria F, Moreno J, Estrada I et al (2008). Variations in circulating cytokine levels during 52 week course of treatment with SSRI for major depressive disorder. Eur Neuropsychopharmacol 18: 917-924.

Himmerich H, Binder EB, Kunzel HE, Schuld A, Lucae S, Uhr M et al (2006). Successful antidepressant therapy restores the disturbed interplay between TNF-alpha system and HPA axis. Biol Psychiatry 60: 882-888.

Himmerich H, Milenovic S, Fulda S, Plumakers B, Sheldrick AJ, Michel TM et al (2010). Regulatory $\mathrm{T}$ cells increased while IL-1beta decreased during antidepressant therapy. J Psychiatr Res 44: 1052-1057.

Hinze-Selch D, Schuld A, Kraus T, Kuhn M, Uhr M, Haack M et al (2000). Effects of antidepressants on weight and on the plasma levels of leptin, TNF-alpha and soluble TNF receptors: a longitudinal study in patients treated with amitriptyline or paroxetine. Neuropsychopharmacology 23: 13-19.

Howren MB, Lamkin DM, Suls J (2009). Associations of depression with C-reactive protein, IL-1, and IL-6: a meta-analysis. Psychosom Med 71: 171-186.

Jazayeri S, Keshavarz SA, Tehrani-Doost M, Djalali M, Hosseini M, Amini $\mathrm{H}$ et al (2010). Effects of eicosapentaenoic acid and fluoxetine on plasma cortisol, serum interleukin-1beta and interleukin-6 concentrations in patients with major depressive disorder. Psychiatry Res 178: 112-115.

Kagaya A, Kugaya A, Takebayashi M, Fukue-Saeki M, Saeki T, Yamawaki S et al (2001). Plasma concentrations of interleukin1beta, interleukin-6, soluble interleukin-2 receptor and tumor necrosis factor alpha of depressed patients in Japan. Neuropsychobiology 43: 59-62.

Keppel WH, Regan DH, Heffeneider SH, McCoy S, Ramsey F (1993). Effects of behavioral stimuli on plasma interleukin-1 activity in humans at rest. J Clin Psychol 49: 777-789.

Kraus T, Haack M, Schuld A, Hinze-Selch D, Koethe D, Pollmacher $\mathrm{T}$ (2002). Body weight, the tumor necrosis factor system, and leptin production during treatment with mirtazapine or venlafaxine. Pharmacopsychiatry 35: 220-225.

Kubera M, Kenis G, Bosmans E, Zieba A, Dudek D, Nowak G et al (2000). Plasma levels of interleukin-6, interleukin-10, and interleukin-1 receptor antagonist in depression: comparison between the acute state and after remission. Pol J Pharmacol 52: 237-241.

Lee SK, Lee HS, Lee TB, Kim DH, Koo JR, Kim YK et al (2004). The effects of antidepressant treatment on serum cytokines and nutritional status in hemodialysis patients. J Korean Med Sci 19: 384-389.

Leo R, Di Lorenzo G, Tesauro M, Razzini C, Forleo GB, Chiricolo G et al (2006). Association between enhanced soluble CD40 ligand and proinflammatory and prothrombotic states in major depressive disorder: pilot observations on the effects of selective serotonin reuptake inhibitor therapy. J Clin Psychiatry 67: 1760-1766.

Maes M, Bosmans E, De Jongh R, Kenis G, Vandoolaeghe E, Neels $H$ (1997). Increased serum IL-6 and IL-1 receptor antagonist concentrations in major depression and treatment resistant depression. Cytokine 9: 853-858.

Maes M, Meltzer HY, Bosmans E, Bergmans R, Vandoolaeghe E, Ranjan $\mathrm{R}$ et al (1995). Increased plasma concentrations of interleukin-6, soluble interleukin-6, soluble interleukin-2 and transferrin receptor in major depression. J Affect Disord 34: 301-309.

Mikova O, Yakimova R, Bosmans E, Kenis G, Maes M (2001). Increased serum tumor necrosis factor alpha concentrations in major depression and multiple sclerosis. Eur Neuropsychopharmacol 11: 203-208.

Miller AH, Maletic V, Raison CL (2009). Inflammation and its discontents: the role of cytokines in the pathophysiology of major depression. Biol Psychiatry 65: 732-741.

Muller N, Schwarz MJ, Dehning S, Douhe A, Cerovecki A, Goldstein-Muller B et al (2006). The cyclooxygenase-2 inhibitor celecoxib has therapeutic effects in major depression: results of a double-blind, randomized, placebo controlled, add-on pilot study to reboxetine. Mol Psychiatry 11: 680-684.

Pace TW, Mletzko TC, Alagbe O, Musselman DL, Nemeroff CB, Miller AH et al (2006). Increased stress-induced inflammatory responses in male patients with major depression and increased early life stress. Am J Psychiatry 163: 1630-1633.

Pavlov VA, Tracey KJ (2005). The cholinergic anti-inflammatory pathway. Brain Behav Immun 19: 493-499.

Piletz JE, Halaris A, Iqbal O, Hoppensteadt D, Fareed J, Zhu H et al (2009). Pro-inflammatory biomakers in depression: treatment with venlafaxine. World J Biol Psychiatry 10: 313-323.

Pizzi C, Mancini S, Angeloni L, Fontana F, Manzoli L, Costa GM (2009). Effects of selective serotonin reuptake inhibitor therapy on endothelial function and inflammatory markers in patients with coronary heart disease. Clin Pharmacol Ther 86: 527-532.

Raison CL, Lowry CA, Rook GA (2010). Inflammation, sanitation, and consternation: loss of contact with coevolved, tolerogenic microorganisms and the pathophysiology and treatment of major depression. Arch Gen Psychiatry 67: 1211-1224.

Reichenberg A, Yirmiya R, Schuld A, Kraus T, Haack M, Morag A et al (2001). Cytokine-associated emotional and cognitive disturbances in humans. Arch Gen Psychiatry 58: 445-452.

Roumestan C, Michel A, Bichon F, Portet K, Detoc M, Henriquet C et al (2007). Anti-inflammatory properties of desipramine and fluoxetine. Respir Res 8: 35.

Selmeczy Z, Szelenyi J, Vizi ES (2003). Intact noradrenaline transporter is needed for the sympathetic fine-tuning of cytokine balance. Eur J Pharmacol 469: 175-181.

Shaked I, Meerson A, Wolf Y, Avni R, Greenberg D, Gilboa-Geffen A et al (2009). MicroRNA-132 potentiates cholinergic anti-inflammatory signaling by targeting acetylcholinesterase. Immunity 31: 965-973.

Sluzewska A, Rybakowski JK, Laciak M, Mackiewicz A, Sobieska M, Wiktorowicz K (1995). Interleukin-6 serum levels in depressed patients before and after treatment with fluoxetine. Ann NY Acad Sci 762: 474-476.

Song C, Halbreich U, Han C, Leonard BE, Luo H (2009). Imbalance between pro- and anti-inflammatory cytokines, and between Th1 and Th2 cytokines in depressed patients: the effect of electroacupuncture or fluoxetine treatment. Pharmacopsychiatry 42: 182-188.

Sutcigil L, Oktenli C, Musabak U, Bozkurt A, Cansever A, Uzun O et al (2007). Pro- and anti-inflammatory cytokine balance in major depression: effect of sertraline therapy. Clin Dev Immunol 2007: 76396.

Thayer JF, Sternberg EM (2010). Neural aspects of immunomodulation: focus on the vagus nerve. Brain Behav Immun 24: 1223-1228.

Tucker P, Ruwe WD, Masters B, Parker DE, Hossain A, Trautman $\mathrm{RP}$ et al (2004). Neuroimmune and cortisol changes in selective serotonin reuptake inhibitor and placebo treatment of chronic posttraumatic stress disorder. Biol Psychiatry 56: 121-128.

Tuglu C, Kara SH, Caliyurt O, Vardar E, Abay E (2003). Increased serum tumor necrosis factor-alpha levels and treatment response in major depressive disorder. Psychopharmacology (Berl) 170: 429-433. 
Tyring S, Gottlieb A, Papp K, Gordon K, Leonardi C, Wang A et al (2006). Etanercept and clinical outcomes, fatigue, and depression in psoriasis: double-blind placebo-controlled randomised phase III trial. Lancet 367: 29-35.

Weber CS, Thayer JF, Rudat M, Wirtz PH, ZimmermannViehoff F, Thomas A et al (2010). Low vagal tone is associated with impaired post stress recovery of cardiovascular, endocrine, and immune markers. Eur J Appl Physiol 109: 201-211.

Wright CE, Strike PC, Brydon L, Steptoe A (2005). Acute inflammation and negative mood: mediation by cytokine activation. Brain Behav Immun 19: 345-350.
Yan Y, Zhang GX, Gran B, Fallarino F, Yu S, Li H et al (2010). IDO upregulates regulatory $\mathrm{T}$ cells via tryptophan catabolite and suppresses encephalitogenic $\mathrm{T}$ cell responses in experimental autoimmune encephalomyelitis. J Immunol 185: 5953-5961.

Yirmiya R, Pollak Y, Barak O, Avitsur R, Ovadia H, Bette M et al (2001). Effects of antidepressant drugs on the behavioral and physiological responses to lipopolysaccharide (LPS) in rodents. Neuropsychopharmacology 24: 531-544.

Yoshimura R, Hori H, Ikenouchi-Sugita A, Umene-Nakano W, Ueda N, Nakamura J (2009). Higher plasma interleukin-6 (IL-6) level is associated with SSRI- or SNRI-refractory depression. Prog Neuropsychopharmacol Biol Psychiatry 33: 722-726. 